\title{
GENERAL MODEL OF RADIATIVE AND CONVECTIVE HEAT TRANSFER IN BUILDINGS: PART II: CONVECTIVE AND RADIATIVE HEAT LOSSES
}

\author{
TOMÁŠ FICKER
}

\author{
Brno University of Technology, Faculty of Civil Engineering, Department of Physics, Veveři 95, 602 00 Brno, \\ Czech Republic \\ correspondence: ficker.t@fce.vutbr.cz
}

\begin{abstract}
The present paper represents the second part of the serial publication, which deals with convective and radiative heat transfers in buildings. The algebraic computational method for combined convective-radiative heat transport in buildings has been proposed. The convective transport of heat has been formulated by means of the correlation functions of the Nusselt number. The radiative heat transfer has been specified by using the radiosity method explained in the first part of the serial publication. The system of transcendent equations has been formed to couple the convective and radiative heat transports. The transcendent system has been solved iteratively, which has facilitated to obtain the optimized surface temperatures as well as the optimized values of the coefficients of heat transfer. On the basis of these optimized values, a more precise overall heat loss has been computed and compared with the results obtained from the thermal standard. The strong and weak points of the both used numerical methods have been discussed.
\end{abstract}

KEYwORDS: Convective heat transfer, radiative heat transfer, room envelope, heat losses, iterative optimization.

\section{INTRODUCTION}

The present paper continues the previous contribution entitled General model of radiative and convective heat transfer in buildings: Part I: Algebraic model of radiative heat transfer [1]. The first part of the serial contribution explained the basics of the radiosity method for quantifying radiative heat transfer in buildings. This method will also be used in the present paper in combination with convective methods so that the heat losses of buildings may be assessed more rigorously.

In the field of building physics, heat and moisture transports are often studied [2 6]. These transports represent a core problem in building performances. The heat transport is often investigated as a heat conduction through building envelopes but the heat transfer inside buildings usually remains overlooked. The heat transfer in closed spaces may consist of conduction, convection and radiation. In thermal equilibrium, these transports compensate not only heat losses going through building envelopes but they may influence the temperatures of interior surfaces that occasionally suffer from the condensation of water vapours.

The electromagnetic waves of heat radiation do not need a mass environment for their propagation in contrast to conductive and convective transports that are incapable of propagating in vacuum. The radiative heat usually represents the most effective transfer of energy. However, in some special cases, other two mechanisms may be in competition with radiation. For this reason, it will be instructive to specify such cases. This will be illustrated in the following introductory paragraphs by comparing effectiveness of heat radiation with other two transfer mechanisms within large and small enclosures.

Let us have a common living room with a heated floor (absolutely black surface with a temperature of $\left.T_{1}=301.15 \mathrm{~K}\right)$. The ceiling of the room is covered with a lime-cement plaster whose emissivity is 0.9 and with a temperature of $T_{2}=291.15 \mathrm{~K}$. The spacing between the floor and the ceiling is $L=2.8 \mathrm{~m}$ and is filled with air that is 'diathermal' owing to radiative heat but owing to heat conduction and convection behaves as a normal fluid. Its thermal conductivity is $\lambda=0.025992 \mathrm{Wm}^{-1} \mathrm{~K}^{-1}$, kinematic viscosity $\nu=15.5473 \cdot 10^{-6} \mathrm{~m}^{2} / \mathrm{s}$ and thermal diffusivity $\alpha=21.9918 \mathrm{~m}^{2} / \mathrm{s}$. Let us consider this inner configuration to be a large hollow cavity with two parallel sides (floor versus ceiling) neglecting the influence of side walls. Let us calculate the amount of heat, which is transferred separately by conduction, convection and radiation per one hour $(t=3600 \mathrm{~s})$ and from one meter squared $\left(S=1 \mathrm{~m}^{2}\right)$.

Heat transferred by conduction (Fourier's relation [5, [6]):

$$
Q_{C}=\lambda \frac{\left(T_{1}-T_{2}\right) \cdot S \cdot t}{L}=0.025992 \frac{10 \cdot 1 \cdot 3600}{2 \cdot 8} \approx 334 \mathrm{~J}
$$


Heat transferred by convection (Nusselt's number $N u$ [7]]):

$$
T_{f}=\left(T_{1}+T_{2}\right) / 2=296.15 \mathrm{~K}
$$

The Rayleigh number:

$$
\begin{gathered}
R a=\frac{g \beta\left(T_{1}-T_{2}\right) L^{3}}{\alpha \nu}=\frac{9.81 \cdot \frac{1}{296.15} \cdot 10 \cdot 2.8^{3}}{21.9918 \cdot 10^{-6} \cdot 15.5473 \cdot 10^{-6}}=2.12675 \cdot 10^{10} \\
\bar{h}=\frac{\lambda}{L} N u=\frac{\lambda}{L}\left\{1+1.44\left[1-\frac{1708}{R a}\right]^{*}+\left[\left(\frac{R a}{5830}\right)^{1 / 3}-1\right]^{*}\right\}=1.442 \mathrm{Wm}^{-2} \mathrm{~K}^{-1}
\end{gathered}
$$

The bracket []$^{*}$ is to be taken as zero if its argument is negative.

$$
Q_{c v}=S \cdot t \cdot \bar{h} \cdot\left(T_{1}-T_{2}\right)=1 \cdot 3600 \cdot 1.442 \cdot 10=51912 \mathrm{~J}
$$

Heat transferred by radiation (mutual radiant capacity $C_{12}$ [5, [6]):

$$
\begin{aligned}
Q_{R}=S \cdot t \cdot q_{12}=S \cdot t \cdot C_{12} \cdot\left[\left(\frac{T_{1}}{100}\right)^{4}\right. & \left.-\left(\frac{T_{2}}{100}\right)^{4}\right]=S \cdot t \cdot \frac{C_{b}}{\frac{1}{\varepsilon_{1}}+\frac{1}{\varepsilon_{2}}-1} \cdot\left[\left(\frac{T_{1}}{100}\right)^{4}-\left(\frac{T_{2}}{100}\right)^{4}\right]= \\
& =1 \cdot 3600 \cdot \frac{5.67}{\frac{1}{0.9}+\frac{1}{1}-1} \cdot\left[(3.0115)^{4}-(2.9115)^{4}\right]=190918.08 \mathrm{~J}
\end{aligned}
$$

By comparing the heat transferred by conduction (Eq. (1)) convection (Eq. (2)) and radiation (Eq. (3)), it is obvious that the transfer realized by the radiation is much more effective than the other two mechanisms. The radiation transmits more than $78.5 \%$ of the heat energy whereas conduction and convection only $21.5 \%$ within the tested room of a common height $2.8 \mathrm{~m}$ between the floor and the ceiling. Such room represents a typical room of a family house.

However, it should be highlighted that it is the large spacing between floor and ceiling that causes such disproportions between transferred amounts of heat. If the spacing is considerably reduced, e.g. to several millimeters (narrow cavity), the convection degenerates into conduction $(N u \approx 1)$ and the amount of heat transferred by conduction and radiation becomes comparable. For example, for the spacing of 4.9011 millimeters, the heat transferred by conduction equals that of radiation, i.e. 190 918 Joule. This is because the radiation mechanism does not depend on the spacing whereas conduction mechanism is reciprocally dependent on the spacing.

Based on foregoing estimations, it can be seen that heat radiation dominates over the other two transfer mechanisms in large inner spaces of buildings. However, the convective contributions in such spaces cannot be neglected, too. For this reason, the discussion should be aimed at the radiative and convective heat transfers. Since the radiative transfer was thoroughly discussed in the preceding contribution [1], the convective transport is the subject of the central interest.

\section{Correlation RELATiOns AND THEIR ROLE IN CONVECTIVE HEAT TRANSPORT}

In research works, the problem of convective heat transport is often solved by using the basic physical conservation laws concerning mass, momentum and energy [8, 9. This leads to the system of governing partial differential equations that have different forms for forced and free convections [10]. These equations are analytically resolvable only in quite simple cases, when surfaces assume uncomplicated shapes. In other, more complicated cases, the discretization and numerical solutions are needed. Such procedures would be rather cumbersome for a quick engineering estimation of a convective heat transport. Fortunately, instead of solving the partial differential equations, the correlation relations associated with the Nusselt number can be used to determine the coefficient of heat transfer $h\left(\mathrm{Wm}^{-2} \mathrm{~K}^{-1}\right)$. This parameter is a crucial parameter for the estimation of the convective heat transport. Correlation functions $f$ associated with Nusselt's number assume different forms for forced and free convections:

$$
N u_{L}=\frac{h L}{\lambda}= \begin{cases}f_{1}(\mathrm{Ra}, \mathrm{Pr}) & \text { free convection } \\ f_{2}(\mathrm{Re}, \mathrm{Pr}) & \text { forced convection }\end{cases}
$$

where Ra, Re, and Pr are Rayleigh's, Reynolds', and Prandtl's similarity numbers [10, respectively. The symbol $L$ is a characteristic dimension of the surface. The particular forms of $f_{1}$ and $f_{2}$ depend on the shapes of surfaces 


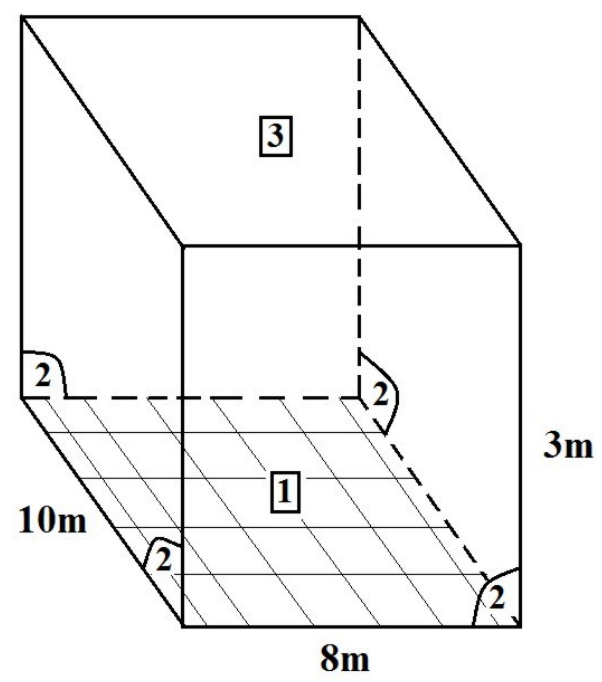

FIGURE 1. Investigated room.

\begin{tabular}{lccccc}
\hline Physical property & $\begin{array}{c}\text { Surface no. 1 (floor) } \\
\text { Interior surface }\end{array}$ & \multicolumn{2}{c}{ Surface no. 2 (side walls) } & \multicolumn{2}{c}{ Surface no. 3 (ceiling) } \\
\cline { 3 - 6 } & & Interior surf. & Exterior surf. & Interior surf. & Exterior surf. \\
\hline $\begin{array}{c}\text { Area } \\
\quad S\left(\mathrm{~m}^{2}\right)\end{array}$ & 80 & 108 & 108 & 80 & 80 \\
$\begin{array}{c}\text { Emissivity } \\
\varepsilon(-)\end{array}$ & 0.95 & 0.85 & 0.90 & 0.90 & 0.90 \\
$\begin{array}{c}\text { Reflectivity } \\
\quad(-)\end{array}$ & 0.05 & 0.15 & 0.10 & 0.10 & 0.10 \\
$\begin{array}{c}\text { Temperature } \\
\quad(\mathrm{K})\end{array}$ & $T_{s i 1}$ & $T_{s i 2}$ & $T_{s e 2}$ & $T_{s i 3}$ & $T_{s e 3}$ \\
$\begin{array}{c}\text { Radiation } \\
\varepsilon E_{b}\left(\mathrm{~W} / \mathrm{m}^{2}\right)\end{array}$ & $5.3865\left(\frac{T_{s i 1}}{100}\right)^{4}$ & $4.8195\left(\frac{T_{s i 2}}{100}\right)^{4}$ & $5.103\left(\frac{T_{s e 2}}{100}\right)^{4}$ & $5.103\left(\frac{T_{s i 3}}{100}\right)^{4}$ & $5.103\left(\frac{T_{s e 3}}{100}\right)^{4}$ \\
$\begin{array}{c}\text { Thermal resistance } \\
R\left(\mathrm{~m}^{2} \mathrm{~K} / \mathrm{W}\right)\end{array}$ & $\infty$ & & & & 1.20 \\
\hline
\end{tabular}

Temperatures: interior $T_{i}=293 \mathrm{~K}\left(20^{\circ} \mathrm{C}\right)$, exterior $T_{e}=258 \mathrm{~K}\left(-15^{\circ} \mathrm{C}\right)$, sky $T_{o}=243 \mathrm{~K}\left(-30^{\circ} \mathrm{C}\right)$.

Speed of wind: $u_{\infty}=20 \mathrm{~m} / \mathrm{s}$.

TABLE 1. Thermal characteristics of the investigated room shown in Fig. 1 .

and are summarized in various monographs. For example, in Ref. [10, a large series of correlation functions are published. The correlation functions result either from the solutions of the governing partial differential equations or, more frequently, from convective experiments. One of the forms of correlation functions has been actually used in the introductory paragraphs to estimate the convective heat transport between the floor and the ceiling of the room.

In order to develop a fast and simple procedure for estimating convective heat transport nearby the inner and outer surfaces of buildings, we will use corresponding correlation functions to determine convective heat transports. These correlations will be coupled with the relations for radiative heat transfers expressed by means of radiosisty concept. In this way, the general combined heat transfer will be described and will serve as a basis for estimating heat losses. Since the correlation relations are mostly represented by transcendent functions, the resulted system of algebraic equations will also be transcendent and this will require iterative solutions.

The goal of the present study is to develop a general numerical procedure for assessing heat losses consisting of radiative and convective components. The procedure should be as simple as possible. The most numerical operations should be realizable by a pocket calculator or excel spreadsheet. Such a procedure should be more tractable in comparison with the governing partial differential equations but, simultaneously, the procedure should yield results whose qualities are comparable with those achieved by the partial differential equations. 


\section{Thermal CharaCteristics of the investigated ROOM}

Fig. 1 shows the scheme of the room whose heat losses are to be investigated. The floor (no. 1) is heated. Since it is well isolated, its heat losses may be neglected. The thermal resistance of the side walls (no. 2) and the ceiling (no. 3) are $R_{2}=2.5 \mathrm{~m}^{2} \mathrm{~K} / \mathrm{W}$ and $R_{3}=1.2 \mathrm{~m}^{2} \mathrm{~K} / \mathrm{W}$, respectively. The temperature of the air on the exterior is $T_{i}=-15^{\circ} \mathrm{C}$. The wind blows on exterior with a speed of $20 \mathrm{~m} / \mathrm{s}$. The temperature of the sky is $T_{o}=-30^{\circ} \mathrm{C}$. The goal is to determine the temperature of the floor $T_{s i 1}$ that would guarantee a room temperature of $T_{i}=20^{\circ} \mathrm{C}$. Other input data are summarized in Tab. 1

In the stationary thermal state, the heat from the heated floor (no. 1) is transported by convection and radiation towards the cooler side walls (no. 2) and the cooler ceiling (no. 3). The cooler surfaces absorb the energies and transport them by conduction through their volumes to their external sides. At the external side, the transported energy is transferred by radiation and convection into the open space (radiation towards the very cold sky). These transport processes will be described by the system of transcendent equations that will contain 5 unknown quantities, namely $T_{s i 1}, T_{s i 2}, T_{s i 13}, T_{s e 2}$ and $T_{s e 3}$ (see Tab. 1). Prior to the formulation of this general system of equations, it is necessary to solve the problem of convection (coefficients of heat transfers) and the heat radiation from the floor to the walls and the ceiling. The next two sections solve both these transports separately.

\section{Estimation of CONVECTIVE heAt TRANSPORT}

Coefficients of heat transfers $h$ are calculated separately for surfaces nos. 1, 2 and 3. These coefficients are termed as follows: $h_{s i 1}$ (floor), $h_{s i 2}$ (internal side of walls), $h_{s i 3}$ (internal side of ceiling), $h_{s e 2}$ (external side of walls), $h_{s e 3}$ (external side of ceiling). For computational purposes, the correlation functions associated with the Nusselt number are used [10 12]. The thermodynamic data for air are taken from the table published in [10].

\subsection{External SURFACES}

The basic input data for calculations of the heat transfer coefficients are the average temperature of convective film $T_{f}$, the speed of wind $u_{\infty}$, kinematic viscosity $\nu$ of air, thermal conductivity of air $\lambda$, characteristic dimension of surface $L$, the Reynolds number $\operatorname{Re}_{L}$, the Prandtl number Pr and the average Nusselt number $N u_{L}$ [10, 11]:

$$
\begin{gathered}
T_{f}=\frac{T_{e}+T_{s e(2)(3)}}{2} \approx T_{e}=258 \mathrm{~K} \\
u_{\infty}=20 \mathrm{~m} / \mathrm{s} \\
\nu(258 \mathrm{~K})=12.152 \cdot 10^{-6} \mathrm{~m}^{2} / \mathrm{s} \\
\lambda(258 \mathrm{~K})=22.94 \cdot 10^{-3} \mathrm{~W} \cdot \mathrm{m}^{-1} \cdot \mathrm{K}^{-1} \\
\operatorname{Pr}(258 \mathrm{~K})=0.718 \\
\operatorname{Re}_{L}=\frac{u_{\infty} \cdot L}{\nu} \\
\mathrm{Nu}_{L}=\frac{h \cdot L}{\lambda}
\end{gathered}
$$

Due to the acting of wind, the forced convection will be established at the external surfaces of the room and this kind of convection will be included in further considerations.

The estimation of the dimension $L$ is problematic because the wind direction is unknown. Fortunately, it may be shown that convective flow along smaller dimension leads to a higher coefficient of heat transfer as compared with the convective flow along a larger dimension. If a higher value of the coefficient of heat transfer is used in calculations, the larger heat losses are obtained, i.e. the results are at the side of a larger safety. In order to illustrate the dependence of the coefficient of heat transfer on the value of $L$, the following calculations are performed twice, i.e. for maximum and minimum of the dimension $L$.

Surface no. 2 (the external side of walls):

$$
L=\left\{\begin{array}{l}
3 \mathrm{~m} \Longrightarrow \operatorname{Re}_{L}=4.9375 \cdot 10^{6} \\
10 \mathrm{~m} \Longrightarrow \operatorname{Re}_{L}=1.6458 \cdot 10^{7}
\end{array}\right.
$$

Since both the values of the Reynolds numbers are much greater than the critical one $\operatorname{Re}_{L}^{(\text {critical })} \approx 5 \cdot 10^{5}$, which is a limit for the transition of the laminar flow into the turbulent flow, it is the turbulent flow that will dominate over the laminar flow. This is also clearly documented by the value of the critical distance $x_{c}=5 \cdot 10^{5} \nu / u_{\infty}=0.3038 \mathrm{~m}$ determining the border for the transition between laminar and turbulent flows. 
The critical distance is very small in comparison with the dimensions of the walls ( $3 \mathrm{~m}$ or $10 \mathrm{~m})$ which means that the turbulent flow will dominate.

The correlation function of the average Nusselt number in the case of the forced, turbulent convection and the plane surface of the arbitrary orientation with respect to the turbulent convection was experimentally established in the following form [10, 11].

$$
\mathrm{Nu}_{L}=0.037 \operatorname{Re}_{L}^{4 / 5} \operatorname{Pr}^{1 / 3}\left(L \gg x_{c}, \operatorname{Re}_{L} \gg \operatorname{Re}_{L}^{(\text {critical })}\right)
$$

From the definition of the Nusselt number (Eq. (11)) and the correlation function (Eq. (13)), it follows:

$$
\begin{gathered}
\mathrm{Nu}_{L}=\frac{h \cdot L}{\lambda} \Longrightarrow h=\frac{\lambda}{L}\left[0.037 \operatorname{Re}_{L}^{4 / 5} \operatorname{Pr}^{1 / 3}\right] \\
h_{s e 2}= \begin{cases}\text { for } L=3 m: & \frac{22.94 \cdot 10^{-3}}{3}\left[0.037 \cdot\left(\frac{20 \cdot 3}{12.152 \cdot 10^{-6}}\right)^{4 / 5} \cdot 0.718^{1 / 3}\right]=57.354 \mathrm{Wm}^{-2} \mathrm{~K}^{-1} \\
\text { for } L=10 m: & \frac{22.94 \cdot 10^{-3}}{10}\left[0.037 \cdot\left(\frac{20 \cdot 10}{12.152 \cdot 10^{-6}}\right)^{4 / 5} \cdot 0.718^{1 / 3}\right]=45.081 \mathrm{Wm}^{-2} \mathrm{~K}^{-1}\end{cases}
\end{gathered}
$$

From Eq. 15, it is clear that a smaller $L$ leads to a larger $h$. To be at the side of a larger safety, it is reasonable to prefer the following value

$$
h_{s e 2}=57.354 \mathrm{Wm}^{-2} \mathrm{~K}^{-1}
$$

Surface no. 3 (the external side of ceiling):

$$
L=\left\{\begin{array}{l}
8 \mathrm{~m} \Longrightarrow \operatorname{Re}_{L}=1.3166 \cdot 10^{7} \\
10 \mathrm{~m} \Longrightarrow \operatorname{Re}_{L}=1.6458 \cdot 10^{7}
\end{array}\right.
$$

The Reynolds numbers in Eq. (17) are much larger than the critical Reynolds number $5 \cdot 10^{5}$ and thus the turbulent convective flow will be assumed in the further calculations as well. The same correlation function of the Nusselt number as in Eqs. (14)/ 15 may be applicable [10, 11]:

$$
h_{s e 2}= \begin{cases}\text { for } L=8 m: & \frac{22.94 \cdot 10^{-3}}{8}\left[0.037 \cdot\left(\frac{20 \cdot 8}{12.152 \cdot 10^{-6}}\right)^{4 / 5} \cdot 0.718^{1 / 3}\right]=47.138 \mathrm{Wm}^{-2} \mathrm{~K}^{-1} \\ \text { for } L=10 \mathrm{~m}: & \frac{22.94 \cdot 10^{-3}}{10}\left[0.037 \cdot\left(\frac{20 \cdot 10}{12.152 \cdot 10^{-6}}\right)^{4 / 5} \cdot 0.718^{1 / 3}\right]=45.081 \mathrm{Wm}^{-2} \mathrm{~K}^{-1}\end{cases}
$$

As seen from Eq. 18, a smaller $L$ again leads to a larger $h$. To be at the side of a larger safety, the following value is preferred

$$
h_{s e 3}=47.138 \mathrm{Wm}^{-2} \mathrm{~K}^{-1}
$$

\subsection{INTERNAL SURFACES}

Inside the room, the floor is the only source of heat. Its warm surface heats the adjacent air that is rising up due to the Archimedes buoyancy force and this is a typical mechanism of the free convection.

The basic input data for calculations of the coefficients of heat transfer are the average temperature of convective film $T_{f}$, kinematic viscosity $\nu$ of air, thermal conductivity of air $\lambda$, thermal diffusivity of air $\alpha$, volumetric thermal expansion coefficient of air $\beta$, gravity acceleration $g$, characteristic dimension of the surface $L$, the Rayleigh number $\mathrm{Ra}_{L}$, the Prandtl number Pr, and the average Nusselt number $\mathrm{Nu}_{L}$ [10, 12].

At first, it is necessary to decide whether the convective flow along the internal surfaces is laminar or turbulent. For this purpose, we need to know the temperature of the convective film $T_{f}$ which is calculated from the room and surface temperatures as their average. This value will be surely very close to the room temperature $T_{i}$ in the case of surfaces nos. 2 and 3 , but not for the surface of the floor (no. 1) due to its heating. For this reason, the estimation of the following thermodynamic values solely concerns the walls and ceiling but the conclusions concerning the floor will be extrapolated.

$$
\begin{gathered}
T_{f}=\frac{T_{i}+T_{s i(2)(3)}}{2} \approx T_{i}=293 \mathrm{~K} \\
\nu(293 \mathrm{~K})=15.267 \cdot 10^{-6} \mathrm{~m}^{2} / \mathrm{s}
\end{gathered}
$$




$$
\begin{gathered}
\lambda(293 \mathrm{~K})=25.74 \cdot 10^{-3} \mathrm{~W} \cdot \mathrm{m}^{-1} \cdot \mathrm{K}^{-1} \\
\alpha(293 \mathrm{~K})=21.576 \cdot 10^{-6} \mathrm{~m}^{2} \mathrm{~s} \\
\beta=\frac{1}{T_{f}}=\frac{1}{293} \mathrm{~K} \\
g=9.81 \mathrm{~ms}^{-2} \\
\operatorname{Pr}(293 \mathrm{~K})=0.7088 \\
\operatorname{Re}_{L}=\frac{u_{\infty} \cdot L}{\nu} \\
\operatorname{Nu}_{L}=\frac{h \cdot L}{\lambda} \\
\operatorname{Ra}_{L}=\frac{g \beta\left(T_{i}-T_{s i(2)(3)}\right) L^{3}}{\nu \alpha}
\end{gathered}
$$

Surface no. 2 (the internal side of walls):

The height of walls is $3 \mathrm{~m}$. This is a characteristic length $L$ along which the free convection develops. To estimate the Rayleigh number $\mathrm{Ra}_{L}$, the temperature difference $\left(T_{i}-T_{s i(2)(3)}\right)$ is needed. However, this difference is unknown, but, on the basis of experience, this difference may amount to about $5 \mathrm{~K}$ (a preliminary guess). The corresponding Rayleigh number calculated according to Eq. 28) then reaches the following value

$$
\operatorname{Ra}_{L}=\frac{9.81 \frac{1}{293} \cdot 5 \cdot 3^{3}}{15.267 \cdot 10^{-6} \cdot 21.576 \cdot 10^{-6}}=1.372 \cdot 10^{10}
$$

This value is by one order larger than the critical Rayleigh number $\operatorname{Ra}_{L}^{(\text {critical })} \approx 10^{9}$ specifying a limit for the transition between the laminar and turbulent flows [10]. The turbulent flow is inevitably present since the critical distance $x_{c}$

$$
x_{c}=\sqrt[3]{10^{9} \cdot \frac{\nu \alpha}{g \beta\left(T_{i}-T_{s i(2)(3)}\right)}}=\sqrt[3]{10^{9} \cdot \frac{15.267 \cdot 10^{-6} \cdot 21.576 \cdot 10^{-6}}{9.81 \frac{1}{293} \cdot 5}}=1.25 \mathrm{~m}
$$

is smaller than the characteristic length $L=3 \mathrm{~m}$. As soon as the laminar flow passes the critical distance $1.25 \mathrm{~m}$, it will start converting into a turbulent flow. This is a typical case of the combined (mixed) convective flow, in which both these types of convections participate almost equally.

The correlation function of the average Nusselt number in the case of the free mixed convection running along the vertical surface was experimentally established in the following form [10]

$$
\left.\mathrm{Nu}_{L}=\left\{0.825+\frac{0.387 \cdot\left(\mathrm{Ra}_{L}\right)^{1 / 6}}{\left[1+\left(\frac{0.492}{\mathrm{Pr}}\right)^{9 / 16}\right]^{8 / 27}}\right\}^{2} \quad \text { (for entire range of } \mathrm{Ra}_{L}\right)
$$

From the definition of the Nusselt number (Eq. (11)) and the correlation function (Eq. (32)), it follows:

$$
\mathrm{Nu}_{L}=\frac{h \cdot L}{\lambda} \Longrightarrow h=\frac{\lambda}{L}\left\{0.825+\frac{0.387 \cdot\left(\mathrm{Ra}_{L}\right)^{1 / 6}}{\left[1+\left(\frac{0.492}{\mathrm{Pr}}\right)^{9 / 16}\right]^{8 / 27}}\right\}^{2}
$$

The length $L=3 \mathrm{~m}$ is utilized as a characteristic dimension in this case:

$$
h_{s i 2}=\frac{25.74 \cdot 10^{-3}}{3} \cdot\left\{0.825+\frac{0.387 \cdot\left(\frac{9.81 \cdot \frac{1}{293}\left(T_{i}-T_{s i 2}\right) \cdot 3^{3}}{15.267 \cdot 10^{-6} \cdot 21.576 \cdot}\right)^{1 / 6}}{\left[1+\left(\frac{0.492}{0.7088}\right)^{9 / 16}\right]^{8 / 27}}\right\}^{2}
$$




$$
\begin{gathered}
h_{s i 2}=0.00858 \cdot\left\{0.825+\frac{0.387 \cdot 37.41738 \cdot\left(T_{i}-T_{s i 2}\right)^{1 / 6}}{1.19305}\right\}^{2} \\
h_{s i 2}=\left\{0.076418+1.124267 \cdot\left(T_{i}-T_{s i 2}\right)^{1 / 6}\right\}^{2}
\end{gathered}
$$

Surface no. 3 (the internal side of ceiling):

The internal surface of the ceiling is a horizontal surface faced downward. At such surface, the convection flow may arise with difficulty in contrast to the convection that runs along the horizontal surface faced upward (such as with floor).

To determine the characteristic convective length $L$ of a horizontal surface is a problem, because the orientation of the convective flow is not known beforehand. As a common practice, the ratio of area $S$ and circumference $C$ of the horizontal surface has been implemented [10, 12]

$$
L \approx \frac{S}{C}
$$

For the internal surface of the ceiling, the characteristic length is $L \approx 80 / 36=2.22 \mathrm{~m}$, which is comparable with the characteristic length of the walls. Thus, the approximate Rayleigh number will be comparable with the Rayleigh number of the wall (Eq. (30)), namely:

$$
\operatorname{Ra}_{L}=\frac{g \beta\left(T_{i}-T_{s i 3}\right) L^{3}}{\nu \alpha}=\frac{9.81 \cdot \frac{1}{293} \cdot 5 \cdot 2.22^{3}}{15.267 \cdot 10^{-6} \cdot 21.576 \cdot 10^{-6}}=5.5604 \cdot 10^{9}
$$

The correlation function of the average Nusselt number in the case of the horizontal cold surface faced downward experiencing free convection has been experimentally found in the following form [10, 12 ]

$$
\mathrm{Nu}_{L}=0.15 \cdot\left(\mathrm{Ra}_{L}\right)^{1 / 3} \quad\left(\text { for the range } 10^{7}<\mathrm{Ra}_{\mathrm{L}}<10^{10}\right)
$$

From the definition of the Nusselt number (Eq. (11)) and the correlation function (Eq. (39p), it follows:

$$
\begin{gathered}
\mathrm{Nu}_{L}=\frac{h \cdot L}{\lambda} \Longrightarrow h_{s i 3}=\frac{\lambda}{L} \cdot 0.15 \cdot\left(\mathrm{Ra}_{L}\right)^{1 / 3} \quad\left(10^{7}<\mathrm{Ra}_{\mathrm{L}}<10^{10}\right) \\
h_{s i 3}=\frac{25.74 \cdot 10^{-3}}{2.22} \cdot 0.15 \cdot\left(\frac{9.81 \cdot \frac{1}{293} \cdot\left(T_{i}-T_{s i 3}\right) \cdot 2.22^{3}}{15.267 \cdot 10^{-6} \cdot 21.576 \cdot 10^{-6}}\right)^{1 / 3} \\
h_{s i 3}=1.7894 \cdot\left(T_{i}-T_{s i 3}\right)^{1 / 3}
\end{gathered}
$$

Surface no. 1 (floor):

The characteristic length $L$ of the horizontal floor is the same as the horizontal ceiling, i.e $L=2.22 \mathrm{~m}$.

The surface of the floor has a higher temperature when compared with the room temperature $T_{i}$ and, thus, the corresponding Rayleigh number will be larger when compared with the ceiling. Supposing $T_{s i 3}-T_{i} \approx 10 \mathrm{~K}$, the Rayleigh number would be $\operatorname{Ra}_{L}=1.1121 \cdot 10^{10}$. The warm horizontal floor whose surface is faced upwards and the Rayleigh number laying in the interval $10^{7}<\operatorname{Ra}_{L}<10^{10}$, has the same correlation function of the Nusselt number as the cold ceiling [10, 11] and, therefore, the relation for the coefficient of heat transfer may be obtained in the same form as for the ceiling:

$$
h_{s i 1}=1.7894 \cdot\left(T_{s i 1}-T_{i}\right)^{1 / 3}
$$

\section{RADIATIVE HEAT}

In the first part of the serial publication [1], the radiative transport of heat in enclosures has been thoroughly discussed and the computational radiosity method [10, 13, 15] has been analysed. The method has been applied not only to closed systems of surfaces but also to open systems. Due to that thorough treatise, there is no need to repeat the basics of that computational method and the particular operations may be presented without detailed explanations.

The matrix of view factors $F_{i j}$ related to the investigated room:

$$
\left(\begin{array}{ccc}
0 & 0.460 & 0.540 \\
0.341 & 0.318 & 0.341 \\
0.540 & 0.460 & 0
\end{array}\right)
$$


Radiosities $W_{i}$ of the inner surfaces:

$$
\begin{gathered}
W_{i}=\varepsilon_{i} E_{b i}+\rho_{i} \sum_{j=1}^{n} F_{i j} W_{j} \quad i, j=1,2,3 \\
W_{1}=0.95 \cdot 5.67 \cdot X_{1}+0.05\left(0.46 W_{2}+0.54 W_{3}\right) \\
W_{2}=0.85 \cdot 5.67 \cdot X_{2}+0.15\left(0.341 W_{1}+0.318 W_{2}+0.34 W_{3}\right) \\
W_{3}=0.90 \cdot 5.67 \cdot X_{3}+0.10\left(0.54 W_{1}+0.46 W_{2}\right)
\end{gathered}
$$

The system of linear algebraic equations 46 is rewritten by means of the Gauss elemination method so that the radiosities $W_{i}$ may be functions of the temperature terms $X_{1}, X_{2}$, and $X_{3}$ :

$$
\begin{aligned}
& W_{1}=5.401810 X_{1}+0.12334 X_{2}+0.14485 X_{3} \mathrm{~W} / \mathrm{m}^{2} \\
& W_{2}=0.306568 X_{1}+5.08046 X_{2}+0.28299 X_{3} \mathrm{~W} / \mathrm{m}^{2} \\
& W_{3}=0.305790 X_{1}+0.24035 X_{2}+5.12380 X_{3} \mathrm{~W} / \mathrm{m}^{2}
\end{aligned}
$$

Heat flows $\phi_{i}$ associated with the inner surfaces:

$$
\begin{gathered}
\phi_{i}=S_{i} \cdot q_{i}=S_{i} \frac{\varepsilon_{i}}{\rho_{i}}\left(E_{b i}-W_{i}\right) \\
\phi_{1}=407.6488 X_{1}-187.4768 X_{2}-220.172 X_{3} \mathrm{~W} \\
\phi_{2}=360.7985 X_{2}-187.6196 X_{1}-173.1899 X_{3} \mathrm{~W} \\
\phi_{3}=393.2640 X_{3}-220.1688 X_{1}-173.0520 X_{2} \mathrm{~W}
\end{gathered}
$$

For further processing, it is important to realize which of the flows $\left\{\phi_{i}\right\}$ is positive (heat emission from the surface into the room) and which of the flows $\left\{\phi_{i}\right\}$ is negative (heat absorption from the room into the surface). According to the analysis presented in the first part of the serial communication [1, the positive flow is associated with the heated floor (warm surface) and the rest of the inner surfaces absorb energies (cold surfaces):

$$
\begin{aligned}
& \phi_{1}>0 \\
& \phi_{2}<0 \\
& \phi_{3}<0
\end{aligned}
$$

\section{TRANSPORT EQUATIONS}

In the preceding sections 3 and 4 , the convective and radiative transports have been solved. The internal and external coefficients of heat transfer $h_{s i 1}, h_{s i 2}, h_{s i 3}, h_{s e 2}, h_{s e 3}$ have been determined in section 3 . Some of these coefficients are in general forms requiring the surface temperatures $T_{s i 1}, T_{s i 2}, T_{s i 3}$. In section 4 , the radiative heat flows $\phi_{1}, \phi_{2}$, and $\phi_{3}$ inside the room have been expressed in dependence on the temperature terms $X_{1}=\left(T_{s i 1} / 100\right)^{4}, X_{2}=\left(T_{s i 2} / 100\right)^{4}$, and $X_{3}=\left(T_{s i 3} / 100\right)^{4}$, which also contain the unknown temperatures $T_{s i 1}, T_{s i 2}, T_{s i 3}$. As soon as the room reaches the stationary thermal state, the heat losses at its external sides are equal to the internal heat transports. The external heat losses comprise losses caused by convection and thermal radiation against the sky. To calculate the radiation against the sky, two other temperatures are required, namely $T_{s e 2}$ and $T_{s e 3}$. By summarizing the unknown temperatures that are required, it is evident that there are five unknown temperatures $T_{s i 1}, T_{s i 2}, T_{s i 3}, T_{s e 2}$ and $T_{s e 3}$ that have to be determined. This problem will be resolved by formulating five equations, the first two of which describe the heat transfer at the external sides whereas the last three equations describe the heat transfers at the internal sides of the room:

$$
\begin{gathered}
\frac{T_{s i 2}-T_{s e 2}}{R_{2}}=h_{s e 2} \cdot\left(T_{s e 2}-T_{e}\right)+\varepsilon_{s e 2} \cdot 5.67 \cdot\left[\left(\frac{T_{s e 2}}{100}\right)^{4}-\left(\frac{T_{0}}{100}\right)^{4}\right] \mathrm{W} / \mathrm{m}^{2} \\
\frac{T_{s i 3}-T_{s e 3}}{R_{3}}=h_{s e 3} \cdot\left(T_{s e 3}-T_{e}\right)+\varepsilon_{s e 3} \cdot 5.67 \cdot\left[\left(\frac{T_{s e 3}}{100}\right)^{4}-\left(\frac{T_{0}}{100}\right)^{4}\right] \mathrm{W} / \mathrm{m}^{2} \\
S_{2} \frac{T_{s i 2}-T_{s e 2}}{R_{2}}=S_{2} \cdot h_{s i 2} \cdot\left(T_{i}-T_{s i 2}\right)-\phi_{2} \mathbf{W} \\
S_{3} \frac{T_{s i 3}-T_{s e 3}}{R_{3}}=S_{3} \cdot h_{s i 3} \cdot\left(T_{i}-T_{s i 3}\right)-\phi_{3} \mathbf{W}
\end{gathered}
$$




$$
S_{1} \cdot h_{s i 1} \cdot\left(T_{s i 1}-T_{i}\right)+\phi_{1}=S_{2} \frac{T_{s i 2}-T_{s e 2}}{R_{2}}+S_{3} \frac{T_{s i 3}-T_{s e 3}}{R_{3}} \mathbf{W}
$$

First Eq. (51) declares the thermal stationarity between the heat conduction inside the walls and their convective and radiative heat transfers at their external sides. Similarly, second Eq. (52) puts the equality between the conductive transport inside the ceiling and the sum of convective and radiative heat transfers at its external side. In short, first two equations (51) and (52) solve the heat losses at the external sides of the investigated room.

Third Eq. (53) defines the numerical equality between the heat conduction inside the walls and the convective and radiative transfers at their internal sides. Similarly, fourth Eq. (54) specifies the stationary equivalence between the conductive transport inside the ceiling and the convective and radiative heat transfers at its internal side. The minus signs with the terms $\phi_{2}$ and $\phi_{2}$ are used because these two terms have a negative numerical value (see Eqs. (50)).

Fifth Eq. (55) describes the thermal equilibrium between the energy coming from the floor and that absorbed by the walls and the ceiling, i.e. it represents the overall heat losses. In short, the last three equations (53), (54), and (55) solve the thermal transfers on the internal sides of the investigated room.

The general system of Eqs. (51) - 55) represents a procedure for finding heat losses of a room whose envelope has been reduced to three surfaces. In a more general case, when the room has a larger number of inner surfaces, the number of equations increases. For example, a room with $N$ cold surfaces and 1 warm surface (heated floor or one radiant panel) would require $2 N+1$ equations whose forms would closely resemble Eqs. (51) - (55). If a source of the heat in the room consisted of several units of the same temperature (e.g. several radiant panels), the total surface of these units would enter the equation related to the warm surface (Eq. (55) ) and, in addition, the radiative heat flow $\phi_{i}$ in that equation would be calculated as the sum of the radiative heat flows generated by all the units.

To prepare the system of Equations (51) - 55) for the numerical processing, it is necessary to insert the data from Tab. 1, the coefficients of heat transfer from section 2 and the heat flows from section 3 in the system of Equations (51) - 55). After inserting all those items, the system of equations assumes the following form:

$$
\begin{gathered}
0.4 \cdot\left(T_{s i 2}-T_{s e 2}\right)=57.354 \cdot\left(T_{s e 2}-258\right)+0.9 \cdot 5.67 \cdot 10^{-8} \cdot\left[\left(T_{s e 2}\right)^{4}-243^{4}\right] \\
0.8333 \cdot\left(T_{s i 3}-T_{s e 3}\right)=47.138 \cdot\left(T_{s e 3}-258\right)+0.9 \cdot 5.67 \cdot 10^{-8} \cdot\left[\left(T_{s e 3}\right)^{4}-243^{4}\right]
\end{gathered}
$$

$$
\begin{aligned}
108 \cdot 0.4 \cdot\left(T_{s i 2}-T_{s e 2}\right)=108 \cdot[0.076418+ & \left.1.124267 \cdot\left(293-T_{s i 2}\right)^{1 / 6}\right]^{2} \cdot\left(293-T_{s i 2}\right)- \\
& -10^{-8}\left(360.7985 \cdot T_{s i 2}^{4}-187.6196 \cdot T_{s i 1}^{4}-173.1899 \cdot T_{s i 3}^{4}\right)
\end{aligned}
$$

$$
\begin{aligned}
80 \cdot 0.8333 \cdot\left(T_{s i 3}-T_{s e 3}\right)=80 \cdot 1.7894 \cdot(293- & \left.T_{s i 3}\right)^{4 / 3}- \\
& -10^{-8}\left(393.264 \cdot T_{s i 3}^{4}-220.1688 \cdot T_{s i 1}^{4}-173.052 \cdot T_{s i 2}^{4}\right)
\end{aligned}
$$

$$
\begin{aligned}
80 \cdot 1.7894 \cdot\left(T_{s i 1}-293\right)^{4 / 3}+10^{8} \cdot\left(407.6488 \cdot T_{s i 1}^{4}\right. & \left.-187.4768 \cdot T_{s i 2}^{4}-220.172 \cdot T_{s i 3}^{4}\right)= \\
& =108 \cdot 0.4 \cdot\left(T_{s i 2}-T_{s e 2}\right)+80 \cdot 0.8333 \cdot\left(T_{s i 3}-T_{s e 3}\right)
\end{aligned}
$$

Eqs. (56) - 60 represent the system of five non-linear transcendent equations. Solving such system may require an iterative procedure. In our case, the Newton iterative method utilizing the Jacobi matrix has been used. The starting guess of five temperatures $\left(T_{s i 1}=303 \mathrm{~K}, T_{s i 2}=295 \mathrm{~K}, T_{s i 3}=292 \mathrm{~K}, T_{s e 2}=265 \mathrm{~K}, T_{s e 3}=260 \mathrm{~K}\right)$ has been used. After six iterations, the resulted temperatures have satisfied the system of Eqs. (56) - 600 satisfactorily.

Two types of computations have been performed. The first type has not included the heat losses caused by the radiation of exterior surfaces against the sky. The second type of computations has taken the external radiation into account. These two types of computations have enabled us to evaluate the influence of external radiation on the overall heat loss.

\subsection{Heat LOSSES Without EXTERnal RAdiation}

In this type of computations, the radiations of external surfaces have been excluded, i.e. Eqs. (56) - (57) have not contained the terms $0.9 \cdot 5.67 \cdot 10^{-8} \cdot\left[\left(T_{s e 2}\right)^{4}-243^{4}\right]$ and $0.9 \cdot 5.67 \cdot 10^{-8} \cdot\left[\left(T_{s e 3}\right)^{4}-243^{4}\right]$, respectively. The resulted temperatures, coefficients of heat transfers and heat losses are shown in Tab. 2

From Tab. 2 it can be seen that the floor temperature amounts to about $23.40^{\circ} \mathrm{C}$ whereas internal surfaces of the walls and the ceilings have lower temperatures, namely about $17^{\circ} \mathrm{C}$. The temperatures of the external 


\begin{tabular}{llcll}
\hline$T_{s i 1}$ & (floor) & $296.3970 \mathrm{~K}\left(\sim 23.40^{\circ} \mathrm{C}\right)$ & $h_{s i 2}$ (walls - interior) & $2.0723 \mathrm{~W} /\left(\mathrm{m}^{2} \mathrm{~K}\right)$ \\
$T_{s i 2}$ & (walls - interior) & $289.8231 \mathrm{~K}\left(\sim 16.82^{\circ} \mathrm{C}\right)$ & $h_{s i 3}$ (ceiling - interior) & $2.6148 \mathrm{~W} /\left(\mathrm{m}^{2} \mathrm{~K}\right)$ \\
$T_{s i 3}$ & (ceiling - interior) & $289.8763 \mathrm{~K}\left(\sim 16.88^{\circ} \mathrm{C}\right)$ & & \\
$T_{s e 2}$ & (walls - exterior) & $258.2204 \mathrm{~K}\left(\sim-14.78^{\circ} \mathrm{C}\right)$ & Heat losses through walls & $1365.2366 \mathrm{~W}$ \\
$T_{s e 3}$ & (ceiling - exterior) & $258.5537 \mathrm{~K}\left(\sim-14.45^{\circ} \mathrm{C}\right)$ & Heat losses through ceiling & $2088.0898 \mathrm{~W}$ \\
$h_{s i 1}$ & (floor) & $2.6888 \mathrm{~W} /\left(\mathrm{m}^{2} \mathrm{~K}\right)$ & Overall heat losses & $3453.3264 \mathrm{~W}$ \\
\hline
\end{tabular}

TABLE 2. Resulting quantities obtained by the computations excluding external heat radiations.

\begin{tabular}{llclc}
\hline$T_{s i 1}$ & (floor) & $296.4994 \mathrm{~K}\left(\sim 23.50^{\circ} \mathrm{C}\right)$ & $h_{s i 2}$ (walls - interior) & $2.0797 \mathrm{~W} /\left(\mathrm{m}^{2} \mathrm{~K}\right)$ \\
$T_{s i 2}$ & (walls - interior) & $289.7869 \mathrm{~K}\left(\sim 16.79^{\circ} \mathrm{C}\right)$ & $h_{s i 3}$ (ceiling - interior) & $2.6328 \mathrm{~W} /\left(\mathrm{m}^{2} \mathrm{~K}\right)$ \\
$T_{s i 3}$ & (ceiling - interior) & $289.8111 \mathrm{~K}\left(\sim 16.81^{\circ} \mathrm{C}\right)$ & & \\
$T_{s e 2}$ & (walls - exterior) & $257.4211 \mathrm{~K}\left(\sim-15.58^{\circ} \mathrm{C}\right)$ & Heat losses through walls & $1398.2026 \mathrm{~W}$ \\
$T_{s e 3}$ & (ceiling - exterior) & $257.5791 \mathrm{~K}\left(\sim-15.42^{\circ} \mathrm{C}\right)$ & Heat losses through ceiling & $2148.7140 \mathrm{~W}$ \\
$h_{s i 1}$ & (floor) & $2.7155 \mathrm{~W} /\left(\mathrm{m}^{2} \mathrm{~K}\right)$ & Overall heat losses & $3546.9166 \mathrm{~W}$ \\
\hline
\end{tabular}

TABLE 3. Resulting quantities obtained by the computations including external heat radiations.

sides of the room envelope have dropped down to $-14^{\circ} \mathrm{C}$ but this is still above the temperature of the external air $\left(-15^{\circ} \mathrm{C}\right)$. However, if the external radiative heat losses are included in the computations, all these temperatures will change their values.

\subsection{Heat LOSSES With EXTERnAl RADiation}

In this type of computations, the radiations of external surfaces have been included, i.e. Eqs. (56) and (57) have contained the terms $0.9 \cdot 5.67 \cdot 10^{-8} \cdot\left[\left(T_{s e 2}\right)^{4}-243^{4}\right]$ and $0.9 \cdot 5.67 \cdot 10^{-8} \cdot\left[\left(T_{s e 3}\right)^{4}-243^{4}\right]$, respectively. The resulting temperatures, coefficients of heat transfers and heat losses are shown in Tab. 3 .

In this second type of computations, one would expect that the overall heat loss will be increased by the amount of energy represented by the external radiative heat computed according to expressions $108 \cdot 0.9$. $5.67 \cdot 10^{-8} \cdot\left[\left(T_{s e 2}\right)^{4}-243^{4}\right]$ plus $80 \cdot 0.9 \cdot 5.67 \cdot 10^{-8} \cdot\left[\left(T_{s e 3}\right)^{4}-243^{4}\right]$. This sum of energies amounts to about $\sim 8720 \mathrm{~W}$. However, the real increase of heat loss is only $(3546.9166-3453.3264) \approx 93.6 \mathrm{~W}$. The explanation of this paradoxical discrepancy is actually easy. From Tab. 3 it follows that the temperatures of external surfaces $-15.58^{\circ} \mathrm{C}$ and $-15.42^{\circ} \mathrm{C}$ lie below the temperature of air $\left(-15^{\circ} \mathrm{C}\right)$, which means that these surfaces absorbed heat due to convection from air. These convective gains can be calculated according to the terms $108 \cdot 57.354 \cdot\left(T_{s e 2}-258\right)$ plus $80 \cdot 47.138 \cdot\left(T_{s e 3}-258\right)$, which provide $\sim 5173.1 \mathrm{~W}$. The convective gains compensate the radiative losses and, in addition, the original convective loss $\sim 3453.3$ (see Tab. 2) is already not active. The net gain is, therefore, much smaller, i.e. $8720-3453.3-5,173.1 \approx 93.6 \mathrm{~W}$, which is in fact the real increase of the overall heat loss. This phenomenon is a consequence of the second law of thermodynamics and can be termed as the 'natural thermal pumping'.

If the radiative heat loss $(8720 \mathrm{~W})$ is considered along with the convective heat gain $(\sim 5173.1 \mathrm{~W})$, then the resulted heat loss can be calculated as the difference $8720-5173.1=3546.9 \mathrm{~W}$, which perfectly agrees with the net heat loss given in Tab. 3

As seen, the very cold sky $\left(-30^{\circ} \mathrm{C}\right)$ is responsible for dropping the temperatures of external surfaces below the temperature of air. Such a situation, when external surfaces are cooler than the air environment, is favourable for condensation of water vapors. For example, if the relative humidity in our case were about $96.6 \%$, the condensate would appear on both the external surfaces (on walls and ceiling) but due to low temperatures, the water droplets would immediately freeze up and the icy cover would arise on the surfaces. Similar situation may occur in summer seasons, when the cold night sky makes solid surfaces cooler as compared with the air and in the early morning wet surfaces may be observed.

\section{Comparison With THERMal STANDARD}

The heat losses of the investigated room may also be evaluated by the proper thermal standard. In our case, the Czech Thermal Standard [16] has been chosen. This Standard specifies fixed coefficients of heat transfer for internal surfaces $\left(h_{i}\right)$ and external surfaces $\left(h_{e}\right)$ according to their orientations and the two seasons of the year (winter and summer):

- $h_{i}=7.7 \mathrm{~W} /\left(\mathrm{m}^{2} \mathrm{~K}\right)$ (internal vertical surface, arbitrary season)

- $h_{i}=5.9 \mathrm{~W} /\left(\mathrm{m}^{2} \mathrm{~K}\right)$ (internal horizontal surface faced downwards, arbitrary season)

- $h_{i}=10.0 \mathrm{~W} /\left(\mathrm{m}^{2} \mathrm{~K}\right)$ (internal horizontal surface faced upwards, arbitrary season) 


\begin{tabular}{llcc}
\hline \multirow{2}{*}{ Physical property } & $\begin{array}{c}\text { Results from transcendent } \\
\text { Eqs. }\end{array}$ & Results from thermal standard \\
\hline$T_{s i 1}$ & (floor) & $23.50{ }^{\circ} \mathrm{C}$ & - \\
$T_{s i 2}$ & (walls - interior) & $16.79{ }^{\circ} \mathrm{C}$ & $18.30^{\circ} \mathrm{C}$ \\
$T_{s i 3}$ & (ceiling - interior) & $16.81^{\circ} \mathrm{C}$ & $16.26^{\circ} \mathrm{C}$ \\
$T_{s e 2}$ & (walls - exterior) & $-15.58^{\circ} \mathrm{C}$ & $-14.47^{\circ} \mathrm{C}$ \\
$T_{s e 3}$ & (ceiling - exterior) & $-15.42^{\circ} \mathrm{C}$ & $-14.12^{\circ} \mathrm{C}$ \\
$h_{s i 1}$ & (floor) & $2.7155 \mathrm{~W} /\left(\mathrm{m}^{2} \mathrm{~K}\right)$ & $10 \mathrm{~W} /\left(\mathrm{m}^{2} \mathrm{~K}\right)$ \\
$h_{s i 2}$ & (walls - interior) & $2.0797 \mathrm{~W} /\left(\mathrm{m}^{2} \mathrm{~K}\right)$ & $7.7 \mathrm{~W} /\left(\mathrm{m}^{2} \mathrm{~K}\right)$ \\
$h_{s i 3}$ & (ceiling - interior) & $2.6328 \mathrm{~W} /\left(\mathrm{m}^{2} \mathrm{~K}\right)$ & $5.9 \mathrm{~W} /\left(\mathrm{m}^{2} \mathrm{~K}\right)$ \\
$h_{s e 2}$ & (ceiling - exterior) & $57.354 \mathrm{~W} /\left(\mathrm{m}^{2} \mathrm{~K}\right)$ & $25 \mathrm{~W} /\left(\mathrm{m}^{2} \mathrm{~K}\right)$ \\
$h_{s e 3}$ & (ceiling - exterior) & $47.138 \mathrm{~W} /\left(\mathrm{m}^{2} \mathrm{~K}\right)$ & $25 \mathrm{~W} /\left(\mathrm{m}^{2} \mathrm{~K}\right)$ \\
\hline
\end{tabular}

TABle 4. Resulted temperatures and coefficients of heat transfer.

- $h_{e}=25 \mathrm{~W} /\left(\mathrm{m}^{2} \mathrm{~K}\right)$ (external surface, arbitrary orientation, winter season)

Heat losses according to the Thermal Standard [16]: Walls:

$$
108 \cdot \frac{20-(-15)}{\frac{1}{7.7}+2.5+\frac{1}{25}}=1415.7992 \mathrm{~W}
$$

Ceiling:

$$
80 \cdot \frac{20-(-15)}{\frac{1}{5.9}+1.2+\frac{1}{25}}=1986.5320 \mathrm{~W}
$$

$$
\text { The overall heat loss : } \quad \sum=3402.3321 \mathrm{~W}
$$

The heat loss $3402.3312 \mathrm{~W}$ is close to the result shown in Tab. 2, which, however, does not include the heat loss due to external radiation against the very cold sky. The difference is only $\sim 51 \mathrm{~W}$. Comparing the heat loss $3402.3312 \mathrm{~W}$ with the result shown in Tab. 3, it is obvious that the difference is larger and amounts to $\sim 145 \mathrm{~W}$. Undoubtedly, the result shown in Tab. 3 is more precise as compared with the calculations according to Eqs. 61) - 63) since the result in Tab. 3 includes not only the influence of external radiation but also the influence of internal radiation inside the room, the actual temperature of fluid flow, turbulent air movement at the external side of the room and the laminar flow of air inside the room.

The simple calculations performed according to the thermal standard [16] (see Eqs. 61] -(63) ) have utilised universal fixed values of the coefficients of heat transfers $h_{i}$ and $h_{e}$. Unfortunately, these fixed values cannot satisfy all varieties of physical conditions inside and outside the room. The coefficients of heat transfer are dependent on the thermodynamic states of the air inside and outside the room (e.g. on temperature, speed of circulating movement, turbulent or laminar flows) and also on the geometrical character of internal and external surfaces (their shapes, length, roughness, etc.). For these reasons, the universal fixed values of the coefficients that are recommended by the thermal standard cannot reliable serve for the accurate estimation of heat transfer but they may only provide an approximate guess for a quick orientation.

Tab. 4 summarizes surface temperatures and the coefficients of heat transfer computed by means of the transport equations (Eqs. (56) - (60) ) and calculated according to the thermal standard [16]. This table offers a comparison of results achieved by both these methods. A clear difference can be seen between results concerning the external temperatures $T_{s e 2}$ and $T_{s e 3}$ achieved by these two methods. The approximate standard calculations have set these temperatures above the air temperature whereas the transport Equations (56) - (60) have found their values below the air temperature as the consequence of the very cold sky (situation favourable for 'natural thermal pumping'). In fact, the standard calculations are not capable of taking into account the effects of cold sky since they do not have any numerical tool for lowering temperatures of external surfaces below the temperature of the external air. This is a significant weak point of the standard calculations.

Some technical literature suggests that the coefficients of heat transfer may be corrected by the radiative contribution as follows

$$
h_{\text {tot }}=h_{\text {convection }}+\Delta h_{\text {radiation }}
$$

Thanks to our separate computations of convective and radiative heat transfers, it is possible to find such corrections and then compare the corrected coefficients with those suggested by the thermal standard [16]. Our convective coefficients of heat transfers $h_{\text {convection }}$ are given by Eqs. $(16),(19),(36),(42)$, and $(43)$. The radiative 


\begin{tabular}{llccc}
\hline Physical property & $\begin{array}{c}\text { Resulted } h_{\text {tot }} \\
\text { from Eqs. } 64-69\end{array}$ & $\begin{array}{c}h \text {-values } \\
\text { from thermal standard }\end{array}$ & Differences \\
\hline$h_{s i 1}$ & (floor) & $12.56 \mathrm{~W} /\left(\mathrm{m}^{2} \mathrm{~K}\right)$ & $10 \mathrm{~W} /\left(\mathrm{m}^{2} \mathrm{~K}\right)$ & $26.0 \%$ \\
$h_{s i 2}$ & (walls - interior) & $5.76 \mathrm{~W} /\left(\mathrm{m}^{2} \mathrm{~K}\right)$ & $7.7 \mathrm{~W} /\left(\mathrm{m}^{2} \mathrm{~K}\right)$ & $25 \%$ \\
$h_{s i 3}$ & (ceiling - exterior) & $8.43 \mathrm{~W} /\left(\mathrm{m}^{2} \mathrm{~K}\right)$ & $5.9 \mathrm{~W} /\left(\mathrm{m}^{2} \mathrm{~K}\right)$ & $43 \%$ \\
$h_{s e 2}$ & (ceiling - exterior) & $56.62 \mathrm{~W} /\left(\mathrm{m}^{2} \mathrm{~K}\right)$ & $25 \mathrm{~W} /\left(\mathrm{m}^{2} \mathrm{~K}\right)$ & $126 \%$ \\
$h_{s e 3}$ & (ceiling - exterior) & $45.75 \mathrm{~W} /\left(\mathrm{m}^{2} \mathrm{~K}\right)$ & $25 \mathrm{~W} /\left(\mathrm{m}^{2} \mathrm{~K}\right)$ & $83 \%$ \\
\hline
\end{tabular}

TABLE 5. The comparison of the coefficients of heat transfer.

corrections $\Delta h_{\text {radiation }}$ may be computed by the radiative heat energies $\phi_{s i 1}, \phi_{s i 2}, \phi_{s i 3}$ given by Eqs. 49 at the internal side of the room and the radiative heat energies at the external side of the room specified by the following expressions $\phi_{s e 2}=0.9 \cdot 5.67 \cdot 10^{-8} \cdot\left[\left(T_{s e 2}\right)^{4}-243^{4}\right]$ and $\phi_{s e 3}=0.9 \cdot 5.67 \cdot 10^{-8} \cdot\left[\left(T_{s e 3}\right)^{4}-243^{4}\right]$ :

$$
\begin{aligned}
\Delta h_{\text {radiation }, s i 1} & =\frac{\phi_{s i 1}}{S_{1} \cdot\left(T_{s i 1}-T_{i}\right)} \\
\Delta h_{\text {radiation }, \text { si } 2} & =\frac{\phi_{s i 2}}{S_{2} \cdot\left(T_{s i 2}-T_{i}\right)} \\
\Delta h_{\text {radiation }, s i 3} & =\frac{\phi_{s i 3}}{S_{3} \cdot\left(T_{s i 3}-T_{i}\right)} \\
\Delta h_{\text {radiation }, s e 2} & =\frac{\phi_{s e 2}}{S_{2} \cdot\left(T_{s e 2}-T_{e}\right)} \\
\Delta h_{\text {radiation }, s e 3} & =\frac{\phi_{s e 3}}{S_{3} \cdot\left(T_{s e 3}-T_{e}\right)}
\end{aligned}
$$

Tab. 5 summarizes the corrected coefficients $h_{t o t}$ and the standard coefficients suggested by the thermal standard [16]. It is evident that the agreement between these two groups of coefficients is not satisfactory. As seen from Tab. 5, there are large differences between the results of these two methods. In some cases, the difference reaches $126 \%$ (see $h_{s e 2}$ in Tab. 5). This indicates that the standard fixed coefficients may hardly be considered as the coefficients that contain reliable contributions from heat radiations. In short, the standard method [16] may be used only for a very approximate estimation of heat losses.

\section{Conclusions}

The presented computational analysis has investigated the convective and radiative heat transports as coupled phenomena. This procedure has consisted of three numerical steps. Within the first step, the convective coefficients of heat transfer have been generally expressed by means of the correlation functions of the Nusselt numbers. In the second step, the radiative heat flows have been generally specified inside and outside the investigated space. In the third and concluding step, the system of transcendent equations has been formed in which the convective and radiative transports have been coupled. The system has been solved iteratively. The results have provided optimized surface temperatures as well as the optimized convective coefficients of heat transfer. On the basis of these optimized values, the total heat loss has been computed.

The presented analysis has shown that the heat losses determined by the thermal standard [16] are underestimated. The problem of this thermal standard is that it uses the constant coefficients of heat transfer $h$ that are actually highly variable quantities. These coefficients are dependent on many parameters, such as the thermodynamical conditions of convective flows, speed of flows, types of flows (free or forced, laminar or turbulent), shapes of surfaces (plain or curved), and topology of surfaces (smooth or rough). For example, a high speed of convective flows may considerably increase the value of the coefficients of heat transfer. All these effects can be taken into account by the combined convective-radiative computational model but not by the standard method [16]. For this reason, it should not be surprising that the coefficients of heat transfer provided by the standard document [16] show so large deviations from the coefficients obtained by the convective-radiative method (see Tab. 5]. Since the thermal standard [16] does not include the influence of the thermodynamical state of external environments (e.g. the cold sky, among others), it is incapable of finding reliable external surface temperatures and thus the effects like 'natural thermal pumping' are beyond the calculational capability of the standard procedure. However, these drawbacks also concern all other thermal methods that use the constant coefficients of heat transfer.

The presented computational analysis based on the combined convective-radiant heat transfer enables to draw several summarizing conclusions: 
- The radiative heat transfer is a dominant energy transport in large enclosures like inner spaces of buildings. However, in narrow air cavities whose widths are only of several millimetres the conductive heat transfer assumes a governing role.

- The combined radiative-convective computational model for assessing the heat transport can be introduced on the basis of the algebraic radiosity method and the correlation functions of the Nusselt number.

- In comparison with the governing partial differential equations, the radiative-convective computational model is more convenient for a common engineering practice since the system of algebraic equations is easier to solve, compared to the system of partial differential equations.

- The accuracy of the radiative-convective model is not worse as compared with the accuracy of the governing partial differential equations since the radative-convective model utilizes correlation functions, most of them have been determined by precise experiments and such experiments are usually closer to reality than discretized differential equations.

- The radiative-convective model includes the majority of the influencing parameters, such as the thermodynamical parameters of convective flows, speed of flows, types of flows (free or forced, laminar or turbulent), shapes of surfaces (plain or curved), and topology of surfaces (smooth or rough).

- Most of the preparatory numerical operations of the radiative-convective model are easy to perform even on a pocket calculator. The model applied to a heated enclosure consists of $2 N+1$ transcendent algebraic equations where the symbol $N$ is a number of cold surfaces. The system is solved iteratively, which facilitates an optimization of results.

- The radiative-convective model is primarily focused on heat losses of buildings. It takes into account the influence of not only the external convective heat losses but also the external radiative heat losses (radiation towards the cold sky). This enables to optimize the temperatures on external surfaces and, thanks to this optimization, the special effects of 'natural thermal pumping' have been revealed and explained.

- One of the valuable properties of the radiative-convective model consists in the possibility to compute the coefficients of heat transfer as a sum of convective and radiative contributions, i.e. $h_{\text {tot }}=h_{\text {convection }}+$ $\Delta h_{\text {radiation. }}$ By comparing these optimized coefficients $h_{\text {tot }}$ with those provided by the thermal standard [16], the large discrepancies have been found (see Tab. 5. This is due to the fact that the thermal standard uses constant coefficients that are optimized neither to actual convective thermodynamical states nor to a real heat radiation of surfaces. As a consequence, the heat losses assessed by such thermal standard may be only very approximate and incapable of taking into account special phenomena like 'natural thermal pumping'.

The developed model treats all of the energy flows in the interior of a structure, through the walls and 'roof' of the structure and between the exterior of the structure and the surrounding environment. This is relevant to computing optimized interior and exterior surface temperatures. The method can compute the energy demand to maintain interior temperatures at desired values. This may be a useful tool in the fields of the building thermal technology and building physics. The model is more advanced as compared with the common methods based on thermal standards. Its results concerning heat losses have a potential to approach the quality of the corresponding results yielded by partial differential models trained in recent thermal research.

\section{REFERENCES}

[1] T. Ficker. General model of radiative and convective heat transfer in buildings: Part I: Algebraic model of radiative heat transfer. Acta Polytechnica 59(3):211 - 223, 2019. DOI:10.14311/AP.2019.59.0211

[2] J. Du, M. Chan, D. Pan, S. Deng. A numerical study on the effects of design/operating parameters of the radiant panel in a radiation-based task air conditioning system on indoor thermal comfort and energy saving for a sleeping environment. Energy and Buildings 151:250 - 262, 2017. DOI:10.1016/j.enbuild.2017.06.052

[3] O. Acikgoz, A. Çebi, A. S. Dalkilic, et al. A novel ANN-based approach to estimate heat transfer coefficients in radiant wall heating systems. Energy and Buildings 144:401 - 415, 2017. DOI:10.1016/j.enbuild.2017.03.043.

[4] T. Ficker. Non-isothermal steady-state diffusion within Glaser's condensation model. International Journal of Heat and Mass Transfer 46(26):5175 - 5182, 2003. DOI:10.1016/S0017-9310(03)00356-9

[5] T. Ficker. Handbook of Building Thermal Technology, Acoustics and Day Lighting. CERM, Brno, 2004.

[6] T. Ficker. Applied Building Physics - Heat Transfer and Condensation in Buildings. BUT, Brno, 2017.

[7] K. Hollands, G. Raithby, L. Konicek. Correlation equations for free convection heat transfer in horizontal layers of air and water. International Journal of Heat and Mass Transfer 18(7):879 - 884, 1975. DOI:10.1016/0017-9310(75)90179-9

[8] D. K. Singh, S. Singh. Combined free convection and surface radiation in tilted open cavity. International Journal of Thermal Sciences 107:111 - 120, 2016. DOI:10.1016/j.ijthermalsci.2016.04.001. 
[9] V. Vivek, A. K. Sharma, C. Balaji. Interaction effects between laminar natural convection and surface radiation in tilted square and shallow enclosures. International Journal of Thermal Sciences 60:70 - 84, 2012. DOI:10.1016/j.ijthermalsci.2012.04.021.

[10] F. P. Incropera, D. P. DeWitt. Fundamentals of Heat Transfer. John Wiley \& Sons, New York, 1981.

[11] S. W. Churchill, H. H. Chu. Correlating equations for laminar and turbulent free convection from a vertical plate. International Journal of Heat and Mass Transfer 18(11):1323 - 1329, 1975. DOI:10.1016/0017-9310(75)90243-4

[12] R. Goldstein, E. Sparrow, D. Jones. Natural convection mass transfer adjacent to horizontal plates. International Journal of Heat and Mass Transfer 16(5):1025 - 1035, 1973. DOI:10.1016/0017-9310(73)90041-0

[13] W. A. Gray, R. Müller. Engineering Calculations in Radiative Heat Transfer. Pergamon Press, Oxford, 1974.

[14] R. Siegel, J. R. Howell. Thermal Radiation Heat Transfer. McGraw-Hill, New York, 1972.

[15] H. C. Hottel. Radiant-heat transmission. In W. H. McAdams (ed.), Heat Transmission. McGraw-Hill Book Co., New York, 1954

[16] ČSN 73 0540-3 - Thermal protection of buildings - Part 3: Design value quantities. Standard, Czech Standardization Agency, 2005. 